\title{
Modeling human influenza infection in the laboratory
}

This article was published in the following Dove Press journal:

Infection and Drug Resistance

3I August 2015

Number of times this article has been viewed

\author{
Kathryn A Radigan' \\ Alexander $\mathrm{V}$ Misharin ${ }^{2}$ \\ Monica $\mathrm{Chi}^{\prime}$ \\ GR Scott Budinger' \\ 'Division of Pulmonary and \\ Critical Care Medicine, ${ }^{2}$ Division \\ of Rheumatology, Northwestern \\ University Feinberg School of \\ Medicine, Chicago, IL, USA
}

Correspondence: Kathryn A Radigan Division of Pulmonary and Critical Care Medicine, Northwestern University Feinberg School of Medicine,

240 E Huron Street, McGaw M300, Chicago, IL 606I I, USA

$\mathrm{Tel}+\mathrm{I} 3129088163$

Fax + I 3129084650

Email k-radigan@northwestern.edu

\begin{abstract}
Influenza is the leading cause of death from an infectious cause. Because of its clinical importance, many investigators use animal models to understand the biologic mechanisms of influenza A virus replication, the immune response to the virus, and the efficacy of novel therapies. This review will focus on the biosafety, biosecurity, and ethical concerns that must be considered in pursuing influenza research, in addition to focusing on the two animal models - mice and ferrets - most frequently used by researchers as models of human influenza infection.
\end{abstract}

Keywords: mice, ferret, influenza, animal model, biosafety

\section{Influenza in the human host Epidemiology and pathogenesis}

Influenza is the leading cause of death from an infectious cause. ${ }^{1}$ During the pandemic of 1918-1919, influenza A virus (IAV) caused as many as 50-100 million deaths. ${ }^{2}$ Even in nonpandemic years, $5 \%-20 \%$ of people in the USA are infected, with the annual average of deaths as a result of influenza infection being $>40,000 .{ }^{3,4}$ The influenza virus is a single-stranded, negative-sense, enveloped RNA virus within the family Orthomyxoviridae. Influenza viruses are the only orthymyxoviridae viruses with the ability to cause infection in humans. There are three types of influenza viruses - influenza A, $\mathrm{B}$, and C, but only influenza viruses A and B cause infection in humans. Possessing eight negative-sense RNA segments that encode 11 or 12 known proteins depending on the overlapping protein-coding region, influenza $\mathrm{A}$ is the most virulent subtype. Each IAV has major surface glycoproteins, including 18 hemagglutinin (HA) and 11 neuraminidase (NA) proteins, but only three major subtypes of $\mathrm{HA}(\mathrm{H} 1, \mathrm{H} 2$, and $\mathrm{H} 3)$ and two subtypes of NA (N1 and N2) have caused pandemics in humans. ${ }^{6}$ The virus has a remarkable ability to undergo periodic changes in the antigenic characteristics of NA and HA. Stepwise point mutations that yield amino acid substitutions in the RNA gene segments as the virus replicates result in "antigenic drift" of the virus. ${ }^{7}$ When two different viruses coinfect a single host, the reassortment of genetic segments within this "mixing vessel" may occur, resulting in "antigenic shift." Exposure of this novel IAV to a naïve population may potentially lead to the next epidemic or pandemic. ${ }^{8}$

In humans, the primary targets for the virus are epithelial cells of the upper and lower respiratory tracts. HA binds to sialic acid residues on glycoproteins of the respiratory epithelial cell surface. ${ }^{9}$ Human influenza viruses bind to sialic acids attached to galactose in an $\alpha-2,6$ configuration, while avian viruses preferentially bind to 
sialic acids attached to galactose in an $\alpha$-2,3 linkage, limiting the transmission of avian influenza viruses to humans. Protease-mediated cleavage of HA results in its endocytosis, whereby the low $\mathrm{pH}$ of the endosome promotes uncoating of the virion, which is required for viral replication. ${ }^{10}$ Progeny virions from cytoplasmic viral replication are transported to the membrane, where they bind to sialic acid residues. Release of the progeny virions from the membrane requires the cleavage of these linkages by NA. ${ }^{11}$ Intracellular viral replication alone can result in the death of the epithelial cell, or the epithelial cell might be killed through activation of innate antiviral immunity.

\section{Clinical findings in humans}

Within a few days of exposure, uncomplicated influenza typically presents acutely with fever, chills, cough, myalgias, headache, lethargy, and sore throat. ${ }^{12}$ Peak temperatures usually occur on the first day of symptoms. Primary viral pneumonia and secondary bacterial pneumonia are the most common complications of influenza, but other complications include central nervous system (CNS) involvement, myositis, myocarditis, and rhabdomyolysis. Primary influenza pneumonia presents with progressive cough, dyspnea, persistent high fever, and hypoxia. Secondary bacterial pneumonia is a common complication of influenza and is responsible for $25 \%$ of all influenza deaths. ${ }^{13}$ These patients may show signs of improvement followed by acute worsening or may exhibit persistent or progressive symptoms. Secondary bacterial pneumonia is associated with significantly higher mortality, particularly when the infecting organism is Staphylococcus aureus or Streptococcus pneumoniae. S. aureus can express cytotoxins such as Panton-Valentine leukocidin, which have the ability to cause life-threatening necrotizing pneumonia. ${ }^{14}$

\section{Transmission of influenza}

Transmission of influenza virus among humans is a major area of study. There are two main modes of transmission of the virus, through contact and air. Contact transmission occurs directly by hand-to-hand contact or indirectly when the infectious virus is transferred from an inanimate object to the hand of a susceptible individual. Airborne transmission occurs when the influenza virus inoculates the respiratory tract directly from the air. This can occur through droplet spray transmission, eg, when the infected person coughs or sneezes, expelling respiratory droplets that come in contact with the nasal mucosa of a susceptible individual. Aerosol transmission occurs when water- and virus-laden respiratory droplets that are exhaled by an infected person desiccate, becoming light enough to remain suspended in the air for minutes to hours and are then inhaled by another individual. Humans are infected by both airborne and contact-based transmission modes, but contact modes are thought to require higher doses of virus for effective transmission. ${ }^{15}$

\section{Prevention and treatment}

The main method of disease control during the influenza season is vaccination. The Centers for Disease Control and Prevention regularly tracks influenza viral isolates from $>100$ national influenza centers in $>100$ countries to monitor disease activity. Every February, the World Health Organization consults with experts to predict components of the annual influenza vaccine that best match the circulating viruses for the following season. ${ }^{16}$ The US Vaccines and Related Biological Products Advisory Committee makes the final decision regarding the composition of the flu vaccine. As seen in the recent $\mathrm{H} 1 \mathrm{~N} 1$ pandemic, vaccine strains are chosen according to previous viral strains. Unfortunately, anticipating pandemics or epidemics created by large antigenic shifts is often impossible.

Antiviral therapy is recommended for all patients with severe disease or high-risk status. ${ }^{17,18}$ Those with severe disease include individuals hospitalized for their illness or those with evidence of lower respiratory tract infection including dyspnea, tachypnea, and/or hypoxia. ${ }^{19}$ Treatment is also indicated for high-risk individuals including residents of chronic care facilities, the elderly, the morbidly obese, pregnant women, or individuals with chronic medical conditions. Adults $<65$ years of age with mild illness and without chronic medical conditions do not require influenza testing, but treatment within 48 hours of onset of their illness may shorten the duration of influenza symptoms by approximately 0.5-3 days. Some researchers incorporate antiviral therapies in their research.

The adamantanes amantadine and rimantadine, prevent replication of the virus by blocking the viral $\mathrm{M} 2$ protein ion channel. This halts fusion of virus and host cell membranes. ${ }^{20}$ Due to the high rates of influenza isolates resistant to adamantanes, the Advisory Committee on Immunization Practices, in 2008, recommended against their routine use for influenza viral infection. ${ }^{17}$ The NA inhibitors zanamivir and oseltamivir, effectively treat both influenza $\mathrm{A}$ and $\mathrm{B}$ viruses by selectively inhibiting NA. ${ }^{9}$ After blocking the active sites of NA, NA inhibitors leave uncleaved sialic acid residues on the surfaces of host cells and influenza viral envelopes, leading to viral aggregation at the host cell surface without a 
mechanism to release the virus. ${ }^{21}$ These antivirals may reduce the duration of symptoms from 1 day to 3 days, especially if administered within 24-48 hours of symptom onset. ${ }^{22,23}$ In cases of severe influenza infection, early initiation of oseltamivir also decreases overall mortality ${ }^{24,25}$ and length of hospitalization. ${ }^{26}$ Increasing resistance to NA inhibitors has been reported, particularly in recent H5N1 and H1N1 influenza A strains. For example, isolates of the 2009 H1N1 virus harbor a $\mathrm{H} 275 \mathrm{Y}$ mutation, resulting in substitution of histidine for tyrosine at position 275 in the NA molecule, which prevents oseltamivir from inhibiting NA activity. ${ }^{27}$ A different mutation has been reported (H274Y) in strains of the influenza A H5N1 virus, resulting in the substitution of tyrosine (encoded by TAC) for histidine (encoded by CAC) at amino acid position 274, conferring high-level resistance to oseltamivir. ${ }^{28,29}$ The development of resistance to therapies emphasizes the need for researchers to identify multipronged approaches to therapy.

\section{Biosafety and ethical concerns Biological containment levels}

Although clearly documented laboratory-associated infections have not been reported, they are theoretically possible and some data suggest that they have occurred. ${ }^{30-32}$ The public health consequences of influenza A infection with unaltered human viruses that have been circulating in the population for years or with murine-adapted viruses are minimal and the risk of severe infection in laboratory workers is very small. Accordingly, cell culture and animal research conducted using circulating influenza strains (eg, H1/H3/B), murineadapted strains, and low-pathogenicity avian influenza strains (eg, H1-4, H6, and H8-16) can usually be performed at Biosafety Level (BSL)-2. Worker protection can be enhanced by regular influenza vaccination.

The study of novel strains or the intentional generation of novel strains poses a greater public health risk. Laboratory personnel could be infected by handling the virus or by coming in contact with respiratory tissues or secretions from infected animals or from contact with other organs when viral dissemination has occurred. It has been estimated that laboratory-associated infections in BSL-3 facilities occur at a rate of approximately 2 per 1,000 laboratory-years. For the approximately ten BSL-3 laboratories in the United States, this corresponds to a $20 \%$ risk of resulting in at least one laboratory-acquired infection over a period of 10 years..$^{33}$ The probability that a laboratory-acquired influenza infection could spread to the population through airborne spread or direct contact is about $10 \%,{ }^{34,35}$ with a range from $5 \%$ to $60 \%{ }^{36}$
Genetic manipulation may alter the host range, pathogenicity, and antigenic composition of the influenza virus. Because of the public health consequences of laboratory-acquired infections, permits from the Animal and Plant Health Inspection Service in the United States are required before investigators can use them for research. These strains usually include highly pathogenic avian influenza (HPAI), the 1918 influenza strain, the H7N9 strain, and the H2N2 strain. ${ }^{37}$ These specific strains require BSL-3 and animal Biosafety Level 3 (ABSL3) practices, procedures, and facilities. Workers must wear a negative-pressure, high-efficiency particular arrestance (HEPA)-filtered respirator or positive air-purifying respirator and change clothes after interaction with the virus. For individuals who work with the 1918 influenza and the HPAI strains, personal showers are required prior to exiting the laboratory. Further occupational health considerations for those working with the HPAI and avian viruses that have infected humans include a detailed proactive plan of action. Some of these plans include requiring storage of baseline serum samples from the workers, annual vaccination, counseling regarding disease symptoms, and establishing a clear plan of action for a suspected laboratory-acquired infection. Special permits may also be required for low-pathogenic avian influenza H5 and $\mathrm{H} 7$ and swine influenza viruses.

\section{Working with poultry and pigs: concern for antigenic shift}

IAVs have the potential to infect a number of different species. Since the HA and NA subtypes of IAVs have been isolated from birds, ${ }^{38}$ there is concern that novel influenza viruses may emerge from birds and infect other mammals including humans. Similarly, swine are susceptible to both human and avian influenza viruses and when coinfected, the animal can serve as a mixing vessel for viral reassortment. ${ }^{39}$ Furthermore, the transmission of influenza viruses from swine to humans is not rare..$^{40}$ These events are thought to underlie the emergence of recent novel $\mathrm{H} 5 \mathrm{~N} 1$ or H7N7 viruses, which represent an ongoing concern. While markets in Southeast Asia, where humans, swine, and poultry coexist, are likely locations for the emergence of novel influenza strains, similar recombination events are possible when humans, pigs, or poultry come in contact in the course of influenza research.

\section{Intentional mutation of the $\mathrm{H} 5 \mathrm{NI}$ virus}

In September 2011, news was released that two groups of scientists had independently created mutant HPAI variants capable of airborne transmission among ferrets. ${ }^{41}$ These 
reports resulted in discussions in both the lay and scientific press with respect to the ethical implications of this research. The controversy was fueled by the high mortality rates $(58 \%)$ observed in the nearly 700 patients infected with the newly emergent HPAI H5N1 viruses between 2003-2015 caused by influenza viruses containing the HA from the A/goose/ Guangdong/1/96 lineage. ${ }^{42,43}$ Publication of the research was delayed while researchers, regulators and funding agencies discussed the rationale, safety measures, and policies in place for this type of research. The papers were eventually published; however, as a result of this controversy, the US Department of Health and Human Services (HHS) developed new regulations that would restrict all research using highly pathogenic H5N1 viruses. These regulations also considered whether the HPAI H5N1 viruses should be a tier-1 HHS select agent, a designation restricted to only a few agents (eg, Ebola or small pox) that are of "the greatest risk of deliberate misuse with the most significant potential for mass casualties or devastating effects to the economy, critical infrastructure, or public confidence." ${ }^{44}$ While this consideration was rejected, the recently released regulations place strict controls on the handling of these viruses for research. ${ }^{45}$ These include an occupational health plan that mandates the use of a respirator with appropriate training, storage of baseline serum samples, influenza vaccination (including a licensed HPAI H5N1 vaccine if available), enrollment in a medical surveillance program, and appropriate placement of isolation and antiviral treatment protocols. The biocontainment guidelines for influenza viruses with the HA from the A/goose/Guangdong/1/96 lineage include BSL-4 and ABSL-4 or BSL-3 agriculture (BSL-3-Ag). ${ }^{45}$ The BSL-3-Ag guidelines include a detailed personnel quarantine policy (eg, no contact with susceptible avian species for at least 5 days after last possible contact with the virus) and more stringent personal protective equipment, including disposable hood or head cover, protective eyewear, respiratory protection, disposable double gloves, disposable protective suit, and disposable shoe or foot covers. For in vitro work, there are additional regulations including air handling, showering, and decontaminations of laboratory liquid effluents. There are also regulations for special caging procedures and the decontamination of solid animal wastes of infected animals.

\section{Use of human volunteers}

The first human influenza viral challenge was performed by Russian scientists in 1936. This study involved 72 subjects who were given an inhalation of atomized droplet suspensions of influenza H1N1 strains. ${ }^{46}$ For decades, similar studies involving experimentally induced influenza infections have been conducted to test the effectiveness, tolerability, and pharmacological properties of influenza therapies. Although the benefits for such studies are clear, even at the time of the first human challenge study with rimantidine, concerns have been raised about the safety of the volunteers and the risk of dissemination of the "challenge" virus into the community. ${ }^{47,48}$ These concerns affect the medicolegal and ethical environment for conducting influenza challenge studies and generally tend to restrict this type of research, necessitating the use of animal models to reflect key aspects of the human disease.

\section{Use of laboratory animals for scientific purposes}

Although the use of animals for influenza research is quite common, researchers must care for and use animals in ways judged to be scientifically, technically, and humanely appropriate. Researchers are also obliged to plan and conduct experiments involving animals with the highest ethical principles. The National Research Council and the Institute of Laboratory Animal Resources have written detailed guidebooks on this topic. ${ }^{49}$

\section{Animal models}

To better mimic influenza A infection in humans, investigators have used a number of animal models, including mice, ferrets, nonhuman primates, guinea pigs, cats, and dogs. As domestic poultry and pigs are often intermediate hosts between birds and humans, their use as animal models are often used to understand influenza transmission to humans; however, because of their susceptibility to circulating viruses, studies in these species require careful safety precautions (as discussed in the previous sections). As a result, most influenza research is carried out in murine and ferret models. When pursuing, reviewing, or critiquing influenza research, it is paramount to keep the animal model used for study into context. Important factors to consider include the susceptibility of the animal to viral infection, its ability to support viral replication, the clinical manifestations of the infection in that animal model, transmission of the virus, and whether the model requires adaptation of the human virus. Therefore, the choice of animal model for any given study must be selected on the basis of the research question.

\section{Ferret model of influenza infection}

Ferrets have widely been used in influenza research since the early $1930 \mathrm{~s} .{ }^{50}$ The main advantages of this model 
are that infection in the ferret closely reflects the clinical manifestations of human influenza infection, airborne transmission of the virus between ferrets can be studied as an end point, and the ferret is susceptible to a variety of nonadapted human influenza isolates. Limitations of the ferret model include its larger size, increased expense on husbandry requirements, the limited availability of reagents for detailed phenotyping, and the lack of genetically modified strains (Figure 1).

Intentional infection of animals with IAVs can be accomplished through the intranasal or intratracheal route. When the virus is administered intranasally, a viral aliquot is placed at the tip of the nose and aspirated during spontaneous breathing. During intratracheal administration, a tube is placed in the trachea under direct visualization and the virus is delivered through the tube directly into the lungs. The route of inoculation and viral strain should be carefully considered in designing influenza challenges in ferrets. ${ }^{51,52}$ For example, Bodewes et $\mathrm{al}^{53}$ found that intratracheal inoculation of ferrets with influenza $\mathrm{A} / \mathrm{H} 5 \mathrm{~N} 1$ caused severe bronchointerstitial pneumonia, while intranasal inoculation caused mild or moderate bronchointerstitial pneumonia in less than half of the ferrets and moderate-to-severe CNS lesions in all of the ferrets. They concluded that intranasal inoculation of influenza $\mathrm{A} / \mathrm{H} 5 \mathrm{~N} 1$ virus resulted in direct innoculation of the brain from the nasal cavity and suggested that CNS lesions contributed more than pulmonary lesions to the pathogenicity of the virus within the ferret model. This finding was especially important as CNS infection is rarely observed in human influenza infection. ${ }^{54}$

A distinct advantage of the ferret model for influenza A infection is the resemblance of the ferret's respiratory tract to that of humans. In particular, ferrets have a similar distribution of $\alpha-2,6$-linkage sialic acid receptors within the respiratory tract, which is likely partially responsible for their susceptibility to human influenza viral strains ${ }^{55}$ In addition, the expression of $\mathrm{N}$-acetylneuraminic acid (Neu5Ac), a sialic acid, has recently been shown to contribute to the susceptibility of ferrets to human-adapted IAV strains. ${ }^{56}$ It has also been noted that both the avian H5N1 and human H3N2 influenza viruses exhibit similar patterns of virus attachment to tissues from both species. ${ }^{57,58}$

Many of the clinical signs of influenza viral infection in humans, including fever, nasal congestion and discharge, anorexia, sneezing, and lethargy, are present in ferrets. ${ }^{59}$ The ferret develops fever as early as 24 hours after inoculation, and high fever has been observed after infection with virulent viruses.$^{60}$ As the ferret has an exquisite sneeze reflex, sneezing is typically a prominent feature for influenza infection in the ferret model; it is so sensitive that researchers often use an anesthetic to intranasally inoculate the animal. ${ }^{50,61}$ Although the clinical presentation of ferrets is quite similar to that in humans, some influenza viruses, eg, the reconstructed 1918 pandemic virus and the $\mathrm{H} 5 \mathrm{~N} 1$ avian virus, manifest as an upper respiratory tract disease in ferrets as opposed to the lower respiratory tract manifestation of disease in humans. ${ }^{62}$ Therefore, influenza infection in ferrets rarely progresses to pneumonia. As mentioned above, ferrets frequently display CNS manifestations of influenza infection, especially when intranasally inoculated with the HPAI H5N1 viruses. ${ }^{63}$

Since the 1930s when it was discovered that asymptomatic ferrets housed with infected ferrets would develop the same disease, the ferret has been used as a model to study viral and host factors responsible for transmission of the influenza virus ${ }^{64}$ Most importantly, the model may be used to assess the pandemic potential of avian and swine influenza strains, to study their reassortment with human circulating viruses, and to compare the transmissibility of antiviral

\begin{tabular}{|c|c|c|}
\hline \multirow[b]{2}{*}{ Advantages } & Mice & Ferrets \\
\hline & $\begin{array}{l}\text { - } \text { Low cost } \\
\text { - Readily available } \\
\text { - Small size } \\
\text { - } \text { Ease of handling/housing } \\
\text { - } \text { with tability of transgenic gene disruptions } \\
\text { - Murine-specific immunological reagents } \\
\text { are widely available } \\
\text { - Well suited to study alternative routes of } \\
\text { inoculation }\end{array}$ & $\begin{array}{l}\text { - Clinical disease manifestation is very similar } \\
\text { to human presentation } \\
\text { - Susceptible to unadapted human influenza } \\
\text { virus isolates } \\
\text { - Able to be used as a model of influenza } \\
\text { transmission }\end{array}$ \\
\hline Disadvantages & $\begin{array}{l}\text { - Necessary to use murine-adapted viruses } \\
\text { - Clinical manifestation in mice is primarily a } \\
\text { lower respiratory tract infection that is } \\
\text { different from typical uncomplicated } \\
\text { influenza } \\
\text { - Not suitable to study transmission of virus }\end{array}$ & $\begin{array}{l}\text { - Limited commercial availability } \\
\text { - Complex husbandry requirements } \\
\text { - } \text { More expensive } \\
\text { - } \text { Outbred genome not fully annotated } \\
\text { possible number of occasional outliers }\end{array}$ \\
\hline
\end{tabular}

Figure I Advantages and disadvantages of the mouse and ferret animal models used for influenza research. 
drug-resistant IAVs. Investigators have used the ferret to examine airborne or contact-driven transmission of the virus either via detection of the virus in respiratory samples or by seroconversion in the uninfected animal. ${ }^{65,66}$

Several groups of investigators have used the ferret model to study the efficacy of novel antiviral agents. The three NA inhibitors, oseltamivir, zanamivir, and peramivir, have been reported to show efficacy in the ferret model. ${ }^{51,67,68}$ These studies must take into account differential bioavailability, pharmacokinetics, and toxicities in ferrets compared with that in humans. For example, oseltamivir phosphate is $75 \%$ orally bioavailable in humans, $30 \%$ in mice, and $11 \%$ in ferrets. ${ }^{69}$ Ferrets were also noted to show toxic effects including lethal seizures with the M2 ion channel inhibitor, amantadine. ${ }^{70}$ Although ferrets could tolerate lower doses, they experienced no improvement in clinical symptoms; however, researchers found that the drug was tolerated and reduced viral shedding and fever when delivered via inhalation. ${ }^{71}$ Because ferrets inoculated with human influenza strains develop active immunity to reinfection with neutralizing antibodies within the serum of inoculated animals, they may be useful for vaccine research. Researchers have reported that the serum of ferrets infected with Influenza A/Puerto Rico/8/34 (PR8) and Philadelphia strains neutralized the infectivity of both strains for mice. ${ }^{64}$

\section{Murine model of influenza infection}

Mice constitute one of the most commonly used models for influenza viral research. Because mice are small, inexpensive, and require minimal husbandry requirements, the mouse is a convenient model of influenza infection. In addition, the large number of genetically mutant murine strains allows investigators to design genetic and loss-of-function approaches to causally link proteins and pathways with disease pathogenesis and to determine the mechanism of action of proposed therapies. Detailed methods to carefully phenotype the severity of the infection in mice and the ability to precisely vary the delivered viral inoculum allow for the detection of small differences that might be important when applied across large populations. Despite these advantages, the mouse is not a natural host for influenza viruses and human IAV subtypes must be adapted to mice for the virus to replicate efficiently within the murine respiratory tract. It is also a poor model of transmission of the virus (Figure 1).

The susceptibility of mice to the influenza virus is dependent on both the strain of the mouse and the strain of the influenza virus. Because the majority of human influenza virus isolates cause only mild infection in mice, investigators typically use one of a handful of murine-adapted strains.
These include Influenza A/Puerto Rico/8/34 (PR8), Influenza A/WSN/33, and Influenza B/Lee/1940. Infection of mice with the WSN and PR8 viral strains results in severe pneumonia and, with sufficiently large viral inocula, in mortality in both $\mathrm{Balb} / \mathrm{C}$ and $\mathrm{C} 57 \mathrm{BL} / 6$ strains. To generate murine-adapted viral strains, investigators passaged isolates of human IAVs in murine tissues (most commonly brain). Other viral strains used that do not require viral adaptation include the 1918 H1N1 pandemic strain, the HPAI H5N1 strain, a few of the H7 subtype and low-pathogenic avian influenza viruses, and the 2009 H1N1 pandemic strains. Because these viral strains do not need prior adaptation, they may be appropriate for studies examining the efficacy of novel therapies when appropriate safety precautions are taken.

While the basis of murine resistance to human influenza viral infection is incompletely understood, an important contributor is the lack of sialic acid moieties with an $\alpha-2,6$ linkage to galactose on the epithelial cells in the mouse. Instead, mice have sialic acids with an $\alpha-2,3$ linkage. Furthermore, the susceptibility of mice to the influenza virus depends on a critical antiviral factor Mx1 protein. Mx1 is a guanosine triphosphatase that is typically induced by type I and type III interferons in the infected host and that subsequently inhibits influenza viral infection by blocking viral transcription and replication. Because most inbred laboratory mice lack the expression of the Mx1 protein, they fail to carry resistance to the virus. ${ }^{72}$ For mice carrying a knocked-in MX1 gene, the $50 \%$ lethal dose of PR 8 virus is $>1,000$ fold higher than that for the parental C57BL/6 mouse. ${ }^{73}$ Similarly, most wild mice are resistant to even the highest viral loads of the PR8 and WSN viruses.

The signs of disease within the murine model of influenza infection are often different from those in humans and differ as a function of the dose administered. Lethal doses result in huddling, ruffled fur, lethargy, anorexia and weight loss, and eventually labored breathing and death. In contrast to humans, mice often develop hypothermia during influenza infection. ${ }^{74}$ Viral replication and tissue damage is typically within the lower respiratory tract, manifesting as a primary viral pneumonia, as opposed to the typical upper respiratory tract replication and damage seen in humans. ${ }^{75,76}$ Histopathology usually reveals significant increase in interstitial inflammatory cells, lung edema, and hemorrhage. ${ }^{75,77}$ Some HPAI viruses spread beyond the mouse respiratory tract to infect the brain, kidney, thymus, liver, heart, and spleen, likely due to the presence of a multibasic cleavage site in the viral HA protein. ${ }^{78-80}$ Parameters to evaluate for viral pathogenicity are mortality, weight loss, viral titers, pathology scores, weight of the lung, oxygen saturation, and activity of the mouse. 
We recently found that intranasal delivery resulted in less severe lung injury along with smaller and more variable viral loads in the lung, but we did not find evidence of viral inoculation of the brain with either method. ${ }^{77}$

The ability of mice to transmit IAVs has been historically controversial. The first experiments examining transmission of influenza virus between mice were reported by Eaton ${ }^{81}$ in the 1940s. Researchers were able to show highly efficient transmission of PR 8 and WSN viruses in his model of influenza infection, with as many as $88 \%$ of the PR 8 and $100 \%$ of the WSN contact mice displaying typical influenza lung pathology. Eaton ${ }^{81}$ also found that there was a higher rate of transmission to contact mice when mice were inoculated with higher doses of influenza virus, that peak transmission rate was observable between 24 hours and 48 hours postinoculation, and that older mice were most susceptible to transmission. For $>20$ years, the findings of Eaton ${ }^{81}$ were unable to be duplicated. Finally, early in the 1960s, Schulman and his colleagues showed that transmission of influenza virus from infected to naïve animals could occur both by contact and via aerosol routes. ${ }^{82-84}$ In contrast to the findings reported by Eaton, ${ }^{81}$ he found poor transmissibility of PR8 and WSN as well as a number of other strains. Overall, the researchers showed that murine transmission of influenza viruses was inefficient and was dependent on both murine strain and the particular murine-adapted influenza strain. Even until recently, researchers have not been able to replicate these findings, revealing that attempts to model influenza transmission have been unsuccessful even with close-contact models of the murine-adapted WSN strain, the 1918 pandemic virus, a highly pathogenic $\mathrm{H} 5 \mathrm{~N} 1$ isolate, human seasonal H1N1, and the 1968 H3N2 strain. ${ }^{85}$ The reason for these differences is unknown, but there is suspicion that it may have to do with differences in viral strain, husbandry practices, or unknown factors affecting the transmission of influenza viruses in mice.

Despite their limitations, murine models of influenza infection are often used to test the safety and efficacy of antiviral drugs. For example, the M2 ion channel inhibitors, amantadine and rimantadine, and the NA inhibitors, oseltamivir, zanamivir, and peramivir, have all showed efficacy in murine models of disease. ${ }^{68,86-90}$

\section{Other animal models}

The albino Hartley strain of guinea pigs is susceptible to nonadapted human influenza virus isolates and it can transmit the virus to other species. This guinea pig is commercially available, small in size, easy to handle and house, and its airway anatomy and physiology more closely resemble humans when compared with other rodent strains. Unfortunately, the guinea pig also lacks the clinical disease manifestations observed in humans and has very few immunological reagents for phenotyping. Other less commonly used animal models used for influenza research include cotton rats, cats, dogs, domestic pigs, nonhuman primates, and hamsters.

\section{Future}

The prevention and successful treatment of influenza viral infection is still limited by our failure to completely understand host-pathogen interactions, inadequate treatment options, and vaccination shortcomings. While the efficacy of currently available therapies in murine models is reassuring, the importance of findings in murine models using historic and murine-adapted viral strains for the human disease is uncertain. Nevertheless, murine and other models allow the design of studies that can help us understand the biology of infection and the host immune response. In addition, innovative technologies may allow researchers to get more information from these models. For instance, researchers have been able to visualize the influenza viral infection in living mice using an engineered replication-competent IAV carrying luciferase reporter gene. ${ }^{91}$ After inoculation of the virus, bioluminescence can be followed, as it correlates with the dosage of infection and viral load within the lung and diminishes with antiviral treatment. This allows the researcher to follow the progression of the influenza virus in real time.

A major concern in the use of murine models to study the innate immune response to IAVs is the presence of important differences between the murine and the human immune systems. In response to this challenge, investigators have developed a humanized murine model..$^{92-94}$ The humanized mouse is an immunodeficient mouse that has been engrafted with human hematopoietic stem cells (HSCs), which, in turn, develop into a functional human immune system. Until recently, the creation of a robust and productive humanized murine model to study the human immune system was impossible. Many attempts to engraft human immune cells into various immunodeficient mice resulted in poor and shortterm engraftment, which was mainly attributed to residual activity of the host's immune system.

A new generation of immunodeficient mouse hosts, which became available in the early 2000s, has dramatically changed the situation. Conceptually, these mice are generated by genetically deleting or introducing genes that prevent the murine immune system from reacting to human allografts. After lethal irradiation, these mice can then be reconstituted using human circulating or bone marrow-derived HSCs or 
fetal circulating monocytes. ${ }^{95}$ The resulting mouse is fully reconstituted with a functional human immune system. The latest humanized murine model among the most immunodeficient to date is the NOD-scid IL $2 r \gamma^{\text {null }}$ mouse, commonly referred to as NSG mouse. While the function of natural killer (NK) cells is affected in non-obese diabetic (NOD) mice, the Scid mutation leads to complete absence of mature $\mathrm{T}$ and $\mathrm{B}$ cells. Furthermore, inactivation of the gamma chain of the interleukin (IL)-2 receptor, which is also known as common cytokine-receptor $\gamma$-chain and which is required for IL-2, IL-4, IL-7, IL-9, IL-15, and IL-21 signaling, further depresses functioning of the innate immune system and completely prevents NK cell development. The only cell types that remain in these immunodeficient mice are neutrophils, monocytes/macrophages, and dendritic cells; however, even these cell types are hypofunctional, which is evident by the lack of inflammatory immune response to bacterial and fungal pathogens. These characteristics not only allow robust engraftment of human peripheral blood mononuclear cells but also support long-term engraftment of human HSCs, either from umbilical cord blood or from granulocyte colony-stimulating factor (G-CSF)-mobilized peripheral blood. Over time, engrafted HSCs undergo multilineage development, resulting in a fully functional human immune system, including $\mathrm{T}, \mathrm{B}$, NK, and dendritic cells, and, to a lesser degree, monocytes/ macrophages and granulocytes.

This humanized murine model revolutionized studies of human-specific infectious species, such as HIV, dengue virus, and recently, Salmonella typhi, to which animals are not susceptible. ${ }^{95}$ Recently, several new substrains of NSG mice, carrying human knock-in or transgenes that improve the function of the transplanted human immune system, have become commercially available. These mice have the potential to contribute significantly to influenza research, especially in the development of vaccines against infectious diseases. A new generation of humanized mice created on Rag-knockout background supports superior development of the myeloid lineage. ${ }^{96}$ Moreover, due to replacement of the murine granulocyte-macrophage colony-stimulating factor (GM-CSF) with human GM-CSF, these mice lack murine alveolar macrophages. However, upon engraftment with human HSCs, their lungs become populated with human alveolar macrophages. Two other new murine strains called MITRG and MISTRG support development of NK cells, in addition to supporting development of myeloid lineage. ${ }^{97}$ These mice can contribute to delineating the role of the innate immune response during influenza A infection.

\section{Conclusion}

Investigators conducting research using IAVs should be familiar with concerns about biosafety, biosecurity, and ethics. Both mice and ferrets provide investigators with unique features for the study of influenza infection. Unfortunately, no model can fully reproduce influenza infection. When pursuing the study of influenza viral infection, the researcher must not only select the most appropriate model in which to investigate the experimental question, but also understand the limitations of that model when interpreting data and making conclusions. New technologies, including the development of luminescent virions and humanized mice, might improve the relevance of information obtained from mouse and other animal models to human disease.

\section{Disclosure}

The authors report no conflicts of interest in this work.

\section{References}

1. Hamilton BE, Minino AM, Martin JA, Kochanek KD, Strobino DM, Guyer B. Annual summary of vital statistics: 2005. Pediatrics. 2007;119(2):345-360.

2. Johnson NP, Mueller J. Updating the accounts: global mortality of the 1918-1920 "Spanish" influenza pandemic. Bull Hist Med. 2002;76(1):105-115.

3. Dushoff J, Plotkin JB, Viboud C, Earn DJ, Simonsen L. Mortality due to influenza in the United States - an annualized regression approach using multiple-cause mortality data. Am J Epidemiol. 2006;163(2): 181-187.

4. Thompson WW, Shay DK, Weintraub E, et al. Influenza-associated hospitalizations in the United States. JAMA. 2004;292(11):1333-1340.

5. Jagger BW, Wise HM, Kash JC, et al. An overlapping protein-coding region in influenza $\mathrm{A}$ virus segment 3 modulates the host response. Science. 2012;337(6091):199-204.

6. Gorbach SL, Bartlett JG, Blacklow NR. Infectious Diseases. 3rd ed. Philadelphia: Lippincott Williams \& Wilkins; 2004.

7. Webster RG, Kendal AP, Gerhard W. Analysis of antigenic drift in recently isolated influenza $\mathrm{A}$ (H1N1) viruses using monoclonal antibody preparations. Virology. 1979;96(1):258-264.

8. Webster RG, Wright SM, Castrucci MR, Bean WJ, Kawaoka Y. Influenza - a model of an emerging virus disease. Intervirology. 1993; $35(1-4): 16-25$.

9. Moscona A. Neuraminidase inhibitors for influenza. $N$ Engl J Med. 2005;353(13):1363-1373.

10. Steinhauer DA. Role of hemagglutinin cleavage for the pathogenicity of influenza virus. Virology. 1999;258(1):1-20.

11. Gubareva LV, Kaiser L, Hayden FG. Influenza virus neuraminidase inhibitors. Lancet. 2000;355(9206):827-835.

12. Zuckerman AJ. Principles and Practice of Clinical Virology. 6th ed. Chichester, UK/Hoboken, NJ: John Wiley \& Sons; 2009.

13. Simonsen L. The global impact of influenza on morbidity and mortality. Vaccine. 1999;17(Suppl 1):S3-S10.

14. Gillet Y, Vanhems P, Lina G, et al. Factors predicting mortality in necrotizing community-acquired pneumonia caused by Staphylococcus aureus containing panton-valentine leukocidin. Clin Infect Dis. 2007;45(3):315-321.

15. Bridges CB, Kuehnert MJ, Hall CB. Transmission of influenza: implications for control in health care settings. Clin Infect Dis. 2003;37(8):1094-1101.

16. Glezen WP. Clinical practice. Prevention and treatment of seasonal influenza. N Engl J Med. 2008;359(24):2579-2585. 
17. Fiore AE, Shay DK, Broder K, et al; Centers for Disease Control and Prevention (CDC), Advisory Committee on Immunization Practices (ACIP). Prevention and control of influenza: recommendations of the Advisory Committee on Immunization Practices (ACIP), 2008. MMWR Recomm Rep. 2008;57(RR-7):1-60.

18. Harper SA, Bradley JS, Englund JA, et al; Expert Panel of the Infectious Diseases Society of America. Seasonal influenza in adults and childrendiagnosis, treatment, chemoprophylaxis, and institutional outbreak management: clinical practice guidelines of the Infectious Diseases Society of America. Clin Infect Dis. 2009;48(8):1003-1032.

19. CDC. Updated Interim Recommendations for the Use of Antiviral Medications in the Treatment and Prevention of Influenza for the 2009-2010 Season. Atlanta: CDC; 2009.

20. Weinstock DM, Zuccotti G. Adamantane resistance in influenza A. JAMA. 2006;295(8):934-936.

21. Palese $P$, Compans RW. Inhibition of influenza virus replication in tissue culture by 2-deoxy-2,3-dehydro-N-trifluoroacetylneuraminic acid (FANA): mechanism of action. J Gen Virol. 1976;33(1): 159-163.

22. Hayden FG, Osterhaus AD, Treanor JJ, et al. Efficacy and safety of the neuraminidase inhibitor zanamivir in the treatment of influenzavirus infections. GG167 Influenza Study Group. NEngl J Med. 1997;337(13): 874-880.

23. Jefferson T, Jones M, Doshi P, Del Mar C. Neuraminidase inhibitors for preventing and treating influenza in healthy adults: systematic review and meta-analysis. BMJ. 2009;339:b5106.

24. McGeer A, Green KA, Plevneshi A, et al; Toronto Invasive Bacterial Diseases Network. Antiviral therapy and outcomes of influenza requiring hospitalization in Ontario, Canada. Clin Infect Dis. 2007;45(12): $1568-1575$.

25. Jain S, Kamimoto L, Bramley AM, et al; 2009 Pandemic Influenza A (H1N1) Virus Hospitalizations Investigation Team. Hospitalized patients with 2009 H1N1 influenza in the United States, April-June 2009. N Engl J Med. 2009;361(20):1935-1944.

26. Lee N, Chan PK, Choi KW, et al. Factors associated with early hospital discharge of adult influenza patients. Antivir Ther. 2007;12(4): 501-508.

27. (US) CfDCaP. Influenza Antiviral Drug Resistance; 2015. Available from: http://www.cdc.gov/flu/about/qa/antiviralresistance.htm Accessed April 23, 2015.

28. de Jong MD, Tran TT, Truong HK, et al. Oseltamivir resistance during treatment of influenza A (H5N1) infection. NEngl J Med. 2005;353(25): 2667-2672.

29. Le QM, Kiso M, Someya K, et al. Avian flu: isolation of drug-resistant H5N1 virus. Nature. 2005;437(7062):1108.

30. Stott DJ, Kerr G, Carman WF. Nosocomial transmission of influenza. Occup Med. 2002;52(5):249-253.

31. Dowdle WR, Hattwick MA. Swine influenza virus infections in humans. J Infect Dis. 1977;136(Suppl):S386-S389

32. Horcajada JP, Pumarola T, Martinez JA, et al. A nosocomial outbreak of influenza during a period without influenza epidemic activity. Eur Respir J. 2003;21(2):303-307.

33. Lipsitch M, Galvani AP. Ethical alternatives to experiments with novel potential pandemic pathogens. PLoS Med. 2014;11(5):e1001646.

34. Klotz LC, Sylvester EJ. The unacceptable risks of a man-made pandemic. Bull At Sci. 2012.

35. Henkel R, Miller T, Weyant R. Monitoring select agent theft, loss and release reports in the United States-2004-2010. Appl Biosaf. 2012;18:171-180.

36. Lloyd-Smith JO, Schreiber SJ, Kopp PE, Getz WM. Superspreading and the effect of individual variation on disease emergence. Nature. 2005;438(7066):355-359.

37. Chosewood LC, Wilson DE; Centers for Disease Control and Prevention (US), National Institutes of Health (US). Biosafety in Microbiological and Biomedical Laboratories. 5th ed. Washington, DC: US Dept of Health and Human Services, Public Health Service, Centers for Disease Control and Prevention, National Institutes of Health; 2009.
38. Webster RG, Peiris M, Chen H, Guan Y. H5N1 outbreaks and enzootic influenza. Emerg Infect Dis. 2006;12(1):3-8.

39. Viroj W. Swine Flu and Pig Borne Diseases. Hauppauge, NY: Nova Science; 2009.

40. Robinson JL, Lee BE, Patel J, et al. Swine influenza (H3N2) infection in a child and possible community transmission, Canada. Emerg Infect Dis. 2007;13(12):1865-1870.

41. [No authors listed]. A long pause. Nat Med. 2013;19(2):113.

42. WHO. Cumulative Number of Confirmed Human Cases for Avian Influenza A(H5N1) Reported to WHO, 2003-2015; 2015. Available from: http://www.who.int/influenza/human_animal_interface/EN_GIP_201 50106CumulativeNumberH5N1cases_corrected.pdf?ua=1. Accessed February 13, 2015

43. Murray CJ, Lopez AD, Chin B, Feehan D, Hill KH. Estimation of potential global pandemic influenza mortality on the basis of vital registry data from the 1918-20 pandemic: a quantitative analysis. Lancet. 2006;368(9554):2211-2218.

44. Centers for Disease Control and Prevention (CDC), Department of Health and Human Services (HHS). Possession, use, and transfer of select agents and toxins. Fed Regist. 2012;77(194):61083-61115.

45. Centers for Disease C, Prevention; Gangadharan D, Smith J, Weyant R. Biosafety recommendations for work with influenza viruses containing a hemagglutinin from the A/goose/Guangdong/1/96 Lineage. MMWR. 2013;62(RR-06):1-7.

46. Smorodintseff A, Tushinsky M, drobyshevskaya AI, Korovin AA, Osetroff AI. Investigation on volunteers infected with the influenza virus. Am J Med Sci. 1937;194(2):159-170.

47. Dawkins AT Jr, Gallager LR, Togo Y, Hornick RB, Harris BA. Studies on induced influenza in man. II. Double-blind study designed to assess the prophylactic efficacy of an analogue of amantadine hydrochloride. JAMA. 1968;203(13):1095-1099.

48. Ison MG, Campbell V, Rembold C, Dent J, Hayden FG. Cardiac findings during uncomplicated acute influenza in ambulatory adults. Clin Infect Dis. 2005;40(3):415-422.

49. Institute of Laboratory Animal Resources (US). Committee on Care and Use of Laboratory Animals. Guide for the Care and Use of Laboratory Animals. Bethesda, MD: US Dept of Health and Human Services, Public Health Service, NIH Publication; 2011:v.

50. Shope RE. The infection of ferrets with swine influenza virus. $J$ Exp Med. 1934;60(1):49-61.

51. Govorkova EA, Ilyushina NA, Boltz DA, Douglas A, Yilmaz N, Webster RG. Efficacy of oseltamivir therapy in ferrets inoculated with different clades of $\mathrm{H} 5 \mathrm{~N} 1$ influenza virus. Antimicrob Agents Chemother. 2007;51(4):1414-1424.

52. Boltz DA, Rehg JE, McClaren J, Webster RG, Govorkova EA. Oseltamivir prophylactic regimens prevent $\mathrm{H} 5 \mathrm{~N} 1$ influenza morbidity and mortality in a ferret model. J Infect Dis. 2008;197(9):1315-1323.

53. Bodewes R, Kreijtz JH, van Amerongen G, et al. Pathogenesis of Influenza A/H5N1 virus infection in ferrets differs between intranasal and intratracheal routes of inoculation. Am J Pathol. 2011;179(1):30-36.

54. Gambotto A, Barratt-Boyes SM, de Jong MD, Neumann G, Kawaoka Y. Human infection with highly pathogenic H5N1 influenza virus. Lancet. 2008;371(9622):1464-1475.

55. Jayaraman A, Chandrasekaran A, Viswanathan K, Raman R, Fox JG, Sasisekharan R. Decoding the distribution of glycan receptors for human-adapted influenza A viruses in ferret respiratory tract. PLoS One. 2012;7(2):e27517.

56. Ng PS, Böhm R, Hartley-Tassell LE, et al. Ferrets exclusively synthesize Neu5Ac and express naturally humanized influenza A virus receptors. Nat Commun. 2014;5:5750.

57. van Riel D, Munster VJ, de Wit E, et al. H5N1 virus attachment to lower respiratory tract. Science. 2006;312(5772):399.

58. van Riel D, Munster VJ, de Wit E, et al. Human and avian influenza viruses target different cells in the lower respiratory tract of humans and other mammals. Am J Pathol. 2007;171(4):1215-1223.

59. Bouvier NM, Lowen AC. Animal models for influenza virus pathogenesis and transmission. Viruses. 2010;2(8):1530-1563. 
60. Zitzow LA, Rowe T, Morken T, Shieh WJ, Zaki S, Katz JM. Pathogenesis of avian influenza A (H5N1) viruses in ferrets. $J$ Virol. 2002;76(9):4420-4429.

61. Matsuoka Y, Lamirande EW, Subbarao K. The ferret model for influenza. Curr Protoc Microbiol. 2009; Chapter 15:Unit15G.12.

62. Maher JA, DeStefano J. The ferret: an animal model to study influenza virus. Lab Anim. 2004;33(9):50-53.

63. Plourde JR, Pyles JA, Layton RC, Vaughan SE, Tipper JL, Harrod KS. Neurovirulence of H5N1 infection in ferrets is mediated by multifocal replication in distinct permissive neuronal cell regions. PLoS One. 2012;7(10):e46605.

64. Francis T, Magill TP. Immunological studies with the virus of influenza. J Exp Med. 1935;62(4):505-516.

65. Herlocher ML, Elias S, Truscon R, et al. Ferrets as a transmission model for influenza: sequence changes in HA1 of type A (H3N2) virus. J Infect Dis. 2001;184(5):542-546.

66. Maines TR, Chen LM, MatsuokaY, et al. Lack of transmission of H5N1 avian-human reassortant influenza viruses in a ferret model. Proc Natl Acad Sci U S A. 2006;103(32):12121-12126.

67. Yun NE, Linde NS, Zacks MA, et al. Injectable peramivir mitigates disease and promotes survival in ferrets and mice infected with the highly virulent influenza virus, A/Vietnam/1203/04 (H5N1). Virology. 2008;374(1):198-209.

68. Mendel DB, Tai CY, Escarpe PA, et al. Oral administration of a prodrug of the influenza virus neuraminidase inhibitor GS 4071 protects mice and ferrets against influenza infection. Antimicrob Agents Chemother. 1998;42(3):640-646.

69. Li W, Escarpe PA, Eisenberg EJ, et al. Identification of GS 4104 as an orally bioavailable prodrug of the influenza virus neuraminidase inhibitor GS 4071. Antimicrob Agents Chemother. 1998;42(3): 647-653.

70. Cochran KW, Maassab HF, Tsunoda A, Berlin BS. Studies on the antiviral activity of amantadine hydrochloride. Ann N Y Acad Sci. 1965; 130(1):432-439.

71. Fenton RJ, Bessell C, Spilling CR, Potter CW. The effects of peroral or local aerosol administration of 1-aminoadamantane hydrochloride (amantadine hydrochloride) on influenza infections of the ferret. J Antimicrob Chemother. 1977;3(5):463-472.

72. Staeheli P, Haller O, Boll W, Lindenmann J, Weissmann C. Mx protein: constitutive expression in $3 \mathrm{~T} 3$ cells transformed with cloned $\mathrm{Mx}$ cDNA confers selective resistance to influenza virus. Cell. 1986;44(1): $147-158$.

73. Grimm D, Staeheli P, Hufbauer M, et al. Replication fitness determines high virulence of influenza A virus in mice carrying functional Mx1 resistance gene. Proc Natl Acad Sci U S A. 2007;104(16):6806-6811.

74. Yang YT, Evans CA. Hypothermia in mice due to influenza virus infection. Proc Soc Exp Biol Med. 1961;108:776-780.

75. Radigan KA, Urich D, Misharin AV, et al. The effect of rosuvastatin in a murine model of influenza A infection. PLoS One. 2012;7(4):e35788.

76. Radigan KA, Morales-Nebreda L, Soberanes S, et al. Impaired clearance of influenza A virus in obese, leptin receptor deficient mice is independent of leptin signaling in the lung epithelium and macrophages. PLoS One. 2014;9(9):e108138.

77. Morales-Nebreda L, Chi M, Lecuona E, et al. Intratracheal administration of influenza virus is superior to intranasal administration as a model of acute lung injury. J Virol Methods. 2014;209:116-120.
78. Joseph T, McAuliffe J, Lu B, Jin H, Kemble G, Subbarao K. Evaluation of replication and pathogenicity of avian influenza a $\mathrm{H} 7$ subtype viruses in a mouse model. J Virol. 2007:81(19):10558-10566.

79. Lu X, Tumpey TM, Morken T, Zaki SR, Cox NJ, Katz JM. A mouse model for the evaluation of pathogenesis and immunity to influenza A (H5N1) viruses isolated from humans. J Virol. 1999;73(7):5903-5911.

80. Maines TR, Lu XH, Erb SM, et al. Avian influenza (H5N1) viruses isolated from humans in Asia in 2004 exhibit increased virulence in mammals. J Virol. 2005;79(18):11788-11800.

81. Eaton MD. Transmission of epidemic influenza virus in mice by contact. J Bacteriol. 1940;39(3):229-241.

82. Schulman JL. Experimental transmission of influenza virus infection in mice. IV. Relationship of transmissibility of different strains of virus and recovery of airborne virus in the environment of infector mice. J Exp Med. 1967;125(3):479-488.

83. Schulman JL, Kilbourne ED. Airborne transmission of influenza virus infection in mice. Nature. 1962;195:1129-1130.

84. Schulman JL, Kilbourne ED. Experimental transmission of influenza virus infection in mice. Ii. Some factors affecting the incidence of transmitted infection. J Exp Med. 1963;118:267-275.

85. Lowen AC, Mubareka S, Tumpey TM, Garcia-Sastre A, Palese P. The guinea pig as a transmission model for human influenza viruses. Proc Natl Acad Sci U S A. 2006;103(26):9988-9992.

86. von Itzstein $\mathrm{M}, \mathrm{Wu} \mathrm{WY}, \mathrm{Kok} \mathrm{GB}$, et al. Rational design of potent sialidase-based inhibitors of influenza virus replication. Nature. 1993;363(6428):418-423.

87. Govorkova EA, Leneva IA, Goloubeva OG, Bush K, Webster RG. Comparison of efficacies of RWJ-270201, zanamivir, and oseltamivir against H5N1, H9N2, and other avian influenza viruses. Antimicrob Agents Chemother. 2001;45(10):2723-2732.

88. Sidwell RW, Smee DF, Huffman JH, et al. Influence of virus strain, challenge dose, and time of therapy initiation on the in vivo influenza inhibitory effects of RWJ-270201. Antiviral Res. 2001;51(3):179-187.

89. Davies WL, Grunert RR, Haff RF, et al. Antiviral activity of 1-adamantanamine (amantadine). Science. 1964;144(3620):862-863.

90. Rabinovich S. Rimantadine therapy of influenza A infection in mice. Antimicrob Agents Chemother. 1972;1(5):408-411.

91. Pan W, Dong Z, Li F, et al. Visualizing influenza virus infection in living mice. Nat Commun. 2013;4:2369.

92. Rongvaux A, Takizawa H, Strowig T, et al. Human hemato-lymphoid system mice: current use and future potential for medicine. Annu Rev Immunol. 2013;31:635-674.

93. Brehm MA, Shultz LD, Greiner DL. Humanized mouse models to study human diseases. Curr Opin Endocrinol Diabetes Obes. 2010;17(2): $120-125$.

94. Akkina R. New generation humanized mice for virus research: comparative aspects and future prospects. Virology. 2013;435(1):14-28.

95. Ito R, Takahashi T, Katano I, Ito M. Current advances in humanized mouse models. Cell Mol Immunol. 2012;9(3):208-214.

96. Willinger T, Rongvaux A, Takizawa H, et al. Human IL-3/GM-CSF knock-in mice support human alveolar macrophage development and human immune responses in the lung. Proc Natl Acad Sci U S A. 2011;108(6):2390-2395.

97. Rongvaux A, Willinger T, Martinek J, et al. Development and function of human innate immune cells in a humanized mouse model. Nat Biotechnol. 2014;32(4):364-372.
Infection and Drug Resistance

\section{Publish your work in this journal}

Infection and Drug Resistance is an international, peer-reviewed openaccess journal that focuses on the optimal treatment of infection (bacterial, fungal and viral) and the development and institution of preventive strategies to minimize the development and spread of resistance. The journal is specifically concerned with the epidemiology of antibiotic

\section{Dovepress}

resistance and the mechanisms of resistance development and diffusion in both hospitals and the community. The manuscript management system is completely online and includes a very quick and fair peerreview system, which is all easy to use. Visit http://www.dovepress.com/ testimonials.php to read real quotes from published authors. 